Acute myocardial infarction 23, 36

Adrenaline 23

Adverse effects 176

Alternans 86

Ambulatory blood pressure monitoring 114

Amiodarone 143

Angina 129

- pectoris 207

Anteroseptal myocardial infarction 11

Apical wall motion 61

Apoptosis 196

Argon gas method 120

Atherectomy 80

Atherosclerosis 1

Athletes 186

Athlete's heart 186

Atrial fibrillation 109

- natriuretic factor 73

\section{CA 1257}

Cardiac damage 114

Cardiomyopathy 61,86

-, inflammatory 120

Carotid artery intima-media thickness 1

Cell culture 80

- survival 17

Chest pain 61

Collateral circulation 53

Congestive heart failure 207

Continuous vectorcardiography 36

Coronary 160

- artery disease 53, 207

- blood flow 120

- circulation 53

- flow reserve 120

C-reactive protein 1

Delivery 176

Differentiation 176

Dobutamine 93

Echocardiography 61, 149

Endomyocardial biopsy 120

Exercise 53

External counterpulsation 129

Familial history 1

Functional capacity 207
Gene expression 73

Genetics 109

Glucose transporter 173

Heart 73

- failure 17

- rate 149

Heterogeneity 73

Hypertrophic cardiomyopathy 93

If inhibitor 149

Imaging 160

Inflammatory infiltrates 120

In-hospital mortality 136

Ischemia 196

Ivabradine 149

\section{KLF5 80}

Left ventricular assist device 17

- - dysfunction 149

- - ejection fraction 23,149

- - function 93

Linkage analysis 109

Microcirculation 120

Microspheres 67

Mitral stenosis 7

Myocardial blood flow 67

- fraction 1

- infarction 29, 176, 207

- oxygen consumption 67

Myocarditis 120

Myosin heavy chain $\beta 73$

Neutralising streptokinase antibodies 36

Noninvasive circulation assist device 129

- reperfusion assessment 36

Non-ischemic cardiomyopathy 136

Noradrenaline 23

Offspring 1

Pacemaker (internal) cardioverter defibrillator 143

Pathophysiology 53

PET scan 11

Plaque 160
Potassium channel 109

Propranolol 67

Quantitative RT-PCR 17

Regional differences 73

Registry 129

Remodelling 196

Renovascular hypertension 114

Reperfusion 196

Restenosis 80

Revascularization 129, 196

Reversibility 61

Right ventricular infarction 41

Risk stratification 136

Smooth muscle cell 80

ST segment elevation, chronic 11

Stem cells 176

Stress echocardiography 93

Stroke volume 149

Sudden cardiac death 186

Syncope 186

T wave 61,86

Takotsubo 61

Tissue Doppler 41

Transcription factor 80

Tricuspid annulus 41

Troponin 29

Tumor markers 7

Unstable 160

- angina 29

Vasodilator capacity 120

Ventricular function, left 61

- pacing 67

- tachyarrhythmia 186

Viability 11

Vulnerable 160

Wall motion abnormalities 93

\section{KARGER}

(c) 2003 S. Karger AG, Base

Fax + 41613061234

E-Mail karger@karger.ch www.karger.com
Accessible online at: www. karger.com/crd 